\title{
Prognostic and Predictive Markers for Treatment Decisions in Early Breast Cancer
}

\author{
Elmar Stickeler \\ Universitätsfrauenklinik Freiburg, Germany
}

\section{Keywords}

Prognosis · Prediction - Early breast cancer - Biomarkers

\section{Summary}

Breast cancer clinically represents a heterogeneous disease. Over the last decades, the integration of prognostic and predictive markers in treatment decisions has led to a more individualized and optimized therapy. While prognosis describes the risk of disease recurrence and disease-related death after diagnosis without the influence of therapy, prediction illustrates the probability of efficacy or response of a specific therapeutic measure. The substantial decline in breast cancer mortality seen over the last 20 years is primarily due to the delivery of adjuvant systemic therapy. It is important that clinical decisions are made to minimize overtreatment, undertreatment, and incorrect treatment. Improved understanding of breast cancer biology together with the utilization of classical biomarkers and the identification of new markers or profiles is increasingly defining who should receive cancer therapy and what therapy offers the best efficacy. The molecular targets as the prerequisite for successful concepts of specific therapies like anti-estrogens, antibodies, or small molecules, have therefore high clinical value in regards to prognosis as well as prediction.

\section{Introduction}

The development of specific systemic treatment options in early breast cancer have led to a substantial decline in breast cancer mortality over the last 20 years [1]. The observed advances are based on the identification of patient subgroups who are in need of treatment and the definition of markers

\section{Schlüsselwörter}

Prognose · Prädiktion · Frühes Mammakarzinom . Biomarker

\section{Zusammenfassung}

Das Mammakarzinom stellt eine klinisch sehr heterogene Erkrankung dar. In den letzten Jahrzehnten hat die Berücksichtigung von prognostischen und prädiktiven Markern zu einer individualisierteren und verbesserten Therapie geführt. Während die Prognose das Risiko des Rezidivs und des Versterbens an der Erkrankung ohne Therapie beschreibt, definiert die Prädiktion die Wahrscheinlichkeit des Ansprechens auf eine bestimmte Behandlung. Die Abnahme der Brustkrebsmortalität über die letzten 20 Jahre ist vor allem auf die Gabe von adjuvanter systemischer Therapie zurückzuführen. Hierbei ist es essentiell, Therapieentscheidungen zu treffen, die Überbehandlung, unzureichende Behandlung und Falschbehandlung vermeiden. Das verbesserte Verständnis der Biologie des Mammakarzinoms mit dem gleichzeitigen Einsatz von klassischen Biomarkern sowie die Identifikation neuer Marker und Genprofile bestimmt zunehmend, welche Patientin wie behandelt werden soll. Die molekularen Targets, als Voraussetzung für erfolgreiche therapeutische Konzepte, wie z.B. der endokrinen Therapie, der Antikörper oder kleinen Moleküle, haben deshalb deshalb einen hohen prädiktiven und letztlich auch prognostischen Wert.

which allow the prediction of the efficacy of certain treatment measures. The best established prognostic markers for breast cancer comprise tumor size, nodal status, metastases, histological tumor type, grading, and age, as well as peritumoral lymphovascular invasion (LVI) [2]. Table 1 summarizes the established markers and lists the grade of recommendation according to the AGO (Arbeitsgemeinschaft Gynäkologische

\section{KARGER \\ Fax +497614520714 \\ Information@Karger.de}

www.karger.com
(C) 2011 S. Karger GmbH, Freiburg

$1661-3791 / 11 / 0063-0193 \$ 38.00 / 0$

Accessible online at:

www.karger.com/brc 
Table 1. Prognostic factors early breast cancer [3]

\begin{tabular}{ll}
\hline Factor & AGO GR \\
\hline Nodal status & ++ \\
Tumor size & ++ \\
Grade & ++ \\
Histological type & ++ \\
Age & ++ \\
Estrogen/progesterone receptor & ++ \\
Peritumoral lymphovascular invasion (L1V1) & + \\
uPA/PAI-1 (ELISA) & + \\
Triple-negative / basal cell like & + \\
\hline
\end{tabular}

AGO = Arbeitsgemeinschaft Gynäkologische Onkologie;

$\mathrm{GR}=$ grade of recommendation; $++=$ highly beneficial for patients,

can be recommended without restrictions, should be performed;

$+=$ limited benefit for patients, can be performed.

Onkologie) Breast Committee guidelines for the diagnosis and treatment of patients with primary and metastatic breast cancer $[2,3]$.

\section{Classical Biomarkers}

Tumor size is a strong and independent prognosticator for breast cancer, even after 20 years of follow-up [4, 5] and exhibits a positive correlation to the axillary lymph node status [6]. However, efficacy of chemotherapy is independent from tumor size.

For early breast cancer, the axillary lymph node status still represents the most important prognostic factor. Node-positive patients exhibit a 4-8 times higher mortality than nodenegative ones [5], and the number of metastatic lymph nodes correlates directly to the risk of recurrence and death [6]. However, the efficacy of adjuvant therapy is not influenced by this parameter. According to international and national guidelines, patients with lymph node-positive breast cancer will be normally treated with adjuvant chemotherapy, independent of receptor status, since they represent the group of patients with the highest benefit from this treatment strategy [1]. For lymph node-negative patients, additional prognostic and predictive markers have to be considered for adequate adjuvant treatment decisions and are still a pertinent issue of ongoing translational research and clinical trials (table 2). Approximately $30 \%$ of node-negative patients will need chemotherapy, but the identification of this subgroup and a clear discrimination against the $70 \%$ of patients who are sufficiently treated by surgery, radiation, and endocrine treatment, is one of the most difficult questions.

The prognostic impact of the histological subtype is limited. Most breast cancers belong to the ductal-invasive and lobular-invasive type which show no significant difference in the clinical course of disease and are therefore no discriminator for treatment decisions. However, some rare breast cancers like the tubular, mucinous, and invasive cribriform type
Table 2. Prognostic factors for node-negative early breast cancer [3]

\begin{tabular}{ll}
\hline Factor & AGO GR \\
\hline Grade & ++ \\
Tumor size & + \\
Age & + \\
uPA/PAI-1 (ELISA) & + \\
Oncotype DX & $+/-$ \\
Mammaprint & $+/-$ \\
\hline AGO & Arbeitsgemeinschaft Gynäkologische Onkologie; \\
GR = grade of recommendation; ++ = highly beneficial for patients, \\
can be recommended without restrictions, should be performed; \\
$+=$ limited benefit for patients, can be performed; +/- = no shown \\
benefit and may be performed only in individual cases, general \\
recommendation cannot be given.
\end{tabular}

do not metastasize frequently and have therefore an excellent prognosis [7].

Histological grade is another prognostic factor for early breast cancer with a strong independent value $[4,5]$. The validity of grading has been compromised by the inter-observer reproducibility. The switch from the traditional Scarff, Bloom, Richardson nuclear system to the modern Elston and Ellis grading system has increased reproducibility significantly [8]. Especially in node-negative patients, higher grade (especially G3) is correlated with an adverse course of disease and endocrine insensitivity, and represents the strongest prognostic factor for this subgroup of patients. These patients should be treated with adjuvant chemotherapy.

Very young age at the time of diagnosis is associated with poor survival. Women younger than 35-40 years exhibit a larger likelihood to develop local recurrences as well as distant metastases in comparison to older patients [4, 5, 9]. This might be due to the fact that they present more frequently with larger tumor size, affected lymph nodes, estrogen receptor (ER) negativity and Her2/neu overexpression [9, 10]. In comparison to patients 40-49 years of age, women aged $<35$ and 35-39 years have a 2.2 and 1.4 higher risk of death, respectively [9]. Young age still qualifies patients as being at high risk with the consequence of an adequate systemic treatment with chemotherapy. In this case, the risk of recurrence and death is comparable to the risk of patients older than 40 years [9]. Even if actual studies including gene signatures cannot support the independence of age as a prognostic factor in multivariate analyses [11], the predictive value of the menopausal status with regard to endocrine therapy options is without doubt important. Surgical or pharmacological ovarian suppression as well as the contraindication for the use of aromatase inhibitors in premenopausal patients underline the importance of this parameter in the daily use for treatment decisions.

LVI is an additional prognostic factor [3, 12]. On the one hand, LVI is regarded as an additional risk factor for axillary lymph node involvement; on the other hand, it is supposed to 
have a special impact for node-negative patients even if the evidence is quite inhomogeneous. Some studies found an up to $60 \%$ higher mortality rate for node-negative patients with a LV1 status in comparison to LV0 tumors [13].

The determination of hormone receptor expression is a widely accepted standard procedure for breast pathology. Interestingly, ER and progesterone receptor (PR) have both prognostic and predictive value, even if the predictive power is much stronger and consecutively more commonly used. Expression of ER reflects a favorable tumor biology, even if its prognostic value is inadequate. The absence of ER predicts earlier recurrence, while ER-positive patients have a constant recurrence rate after 5 years [14].

Of highest clinical importance is the predictive value of ER, since its presence correlates with the benefit of adjuvant endocrine therapy [1]. In this regard, it is of interest that the level of ER expression directly correlates with the probability of treatment response and efficacy, especially for the treatment with tamoxifen [1]. Furthermore, there is growing evidence for a significantly better response to chemotherapy for hormone receptor-negative patients [15].

The independent value of PR expression is an ongoing discussion. While the prognostic power is inconclusive and not confirmed, even the predictive significance is being debated. The EBCTCG metaanalysis could not confirm the earlier postulated independent predictive power of PR for treatment response, even if clinical observations support an increased benefit for ER- and PR-positive tumors in comparison to ER-positive/PR-negative tumors [16].

The methodology for ER and PR measurement has changed over the last decades and is currently based on immunohistochemistry. The percentage of stained tumor cells or, in addition, a score as a product of percentage of stained cells and staining intensity (Remmele-Stegner score, $0-12$ ) is widely used [17]. While the international St. Gallen Consensus Conference defined any staining as the threshold for predicted endocrine responsiveness of the tumor [18], the AGO guidelines specify responsiveness with a staining of $\geq 1 \%$ [3].

The impact of Her2/neu on breast cancer biology, the clear definition of a molecular target, and the development of a highly effective therapeutic option in the application of the monoclonal antibody trastuzumab form one of the most dramatic changes in breast cancer therapy over the last decades and have opened up the field of personalized, targeted treatment besides endocrine therapy. Her2/neu as a member of the transmembraneous Her family is overexpressed in 15$20 \%$ of tumors, mainly due to amplification of the Her $2 /$ neu gene. Overexpression is strongly correlated with aggressive tumor type, downregulation of hormone receptors, and induced proliferation, with consecutive decreased overall survival, although these observations are still being debated for node-negative patients without adjuvant therapy. While some trials were not able to detect a biological impact of Her2/neu [19], there is growing evidence for an independent prognostic power of Her2/neu in this specific subgroup of patients $[3,20]$. However, Her $2 /$ neu is an important and routinely used predictive marker. Besides retrospective analyses which showed a reduced efficacy with regard to certain endocrine (tamoxifen) and cytotoxic (cyclophosphamide, methotrexate, 5-fluorouracil) strategies [19], the predictive power of Her2/neu is based on the application of the monoclonal antibody trastuzumab. Only patients with Her $2 /$ neu overexpression, determined by immunohistochemistry $(\geq 30 \%$ intense and complete staining) or in situ hybridization $(\geq 6.0$ signals per nucleus by single color or signal ratio $\geq 2.2$ for Her2/neu versus centromere 17 for dual color), will have a clinical benefit from a trastzumab-based therapy with a consistently confirmed $50 \%$ reduced risk of recurrence $[3,21,22]$.

\section{New and Innovative Biomarkers}

A broad variety of new biomarkers with potential prognostic or predictive value are discussed in the literature, but only a few have proven to represent an evidence-based gain for daily use.

The tumor-associated fibrinolytic factors urokinase-type plasminogen activator (uPA) and its inhibitor type 1 (PAI-1) are important promoters of tumor invasion and metastasis. The uPA/PAI-1 assay is based on a standardized enzymelinked immunosorbent assay (ELISA) to measure the protein levels in fresh tumor samples. Single clinical trials as well a recently published metaanalysis with $>8,000$ patients confirmed the prognostic value of uPA/PAI-1 [23]. Node-negative patients with low uPA/PAI-1 levels have a very low risk of recurrence, and in the final analysis of the multicentric prospective Chemo N0 trail a 10-year survival rate of nearly $90 \%$ without any adjuvant treatment was observed [24]. Besides retrospective analyses showing a clear benefit for adjuvant chemotherapy in patients with high versus low uPA/PAI levels, the prospectively designed international multicentric NNBC-3 study will address the question of treatment optimization for node-negative patients with a taxane/anthracyclinebased chemotherapy regimen with regard to uPA/PAI expression. Based on the well established standardization and the solid scientific evidence, uPA/PAI-1 detection is recommended by the AGO Breast Committee (AGO LOE 1a, GR $\mathrm{A},+$ ) as well as by the American Society of Clinical Oncology (ASCO) guidelines, especially for the group of G2 node-negative patient, as a tool for treatment decisions [3].

Proliferation has been recognized for a long time as an important prognosticator in breast cancer. Ki-67 represents a strong proliferation marker and has been gaining more interest over the last years. Patients with highly proliferating tumors exhibit an increased benefit from adjuvant therapy in comparison to patients with low or intermediate proliferation activity [25]. In retrospective analyses, higher values of Ki-67 were associated with adverse prognostic factors such as Her2/ 
neu expression, higher grading, or LVI, and with worse disease-free survival with a hazard ratio (HR) of 1.8 in comparison to tumors with low Ki-67 expression [25]. Since prospective validation is still missing, a general recommendation for Ki-67 determination cannot be given. However, this factor represents an additional potential prognostic marker in selected cases and is gaining more importance due to its role in defining the different intrinsic subtypes of breast cancer [3].

Over the last years, molecular characterization of breast cancer has gained more and more importance [26, 27]. The profound analysis of gene expression profiles has led to the definition of 5 different molecular intrinsic subtypes of breast cancer: ER-positive/luminal A and B, basal-like, ErbB2-positive, and normal breast, which are associated with differences in clinical outcome. The intrinsic subtypes as distinct entities were found to have a significant impact on recurrence-free survival in untreated patients and remained significant in multivariate analysis incorporating standard prognostic factors such as ER status, histological grade, tumor size, and lymph node status. The basal-like subtype - which is mostly G3-differentiated, expressing C5/6 cytokeratins, and negative for ER, PR, and Her2/neu - is characterized by an unfavorable prognosis and represents a potential predictor for specific adjuvant systemic treatment, which is currently under investigation [28]. According to the St. Gallen Consensus 2011, the intrinsic subtypes can be defined by immunohistochemistry, in analogy to the classification recommended by Cheang et al. [29] using ER, PR, Her2/neu, and Ki-67, respectively: i) Luminal A = ER- and/or PR-positive, Her2/neu-negative, Ki-67 low (<14\%); ii) Luminal B (Her2/neu-negative) = ER- and/or PR-positive, Her2/neu-negative, Ki-67 high $(<14 \%)$; iii) Luminal B (Her2/neu-positive) $=$ ER- and/or PR-positive, Her2/neu overexpression/amplification, Ki-67 low or high; iv) Her2/neu-positive (not luminal) = ER- and PRnegative, Her2/neu overexpression/amplification; v) Basallike, triple-negative $($ ductal $)=$ ER- and PR-negative, Her2/ neu-negative.

The significant discrepancies between the clinical and molecular classification become apparent for the so-called triple-negative breast cancers (ER-, PR-, Her2/neu-negative) which are defined immunohistochemically. This subgroup is not identical to the molecularly defined basal-like subtype and underlines the fact that ER and Her2/neu status are not accurate surrogates for the true intrinsic subtype status. As a consequence, the optimal classification system for breast cancer subtypes to guide therapeutic decision-making has to yet be defined. Nevertheless, the triple-negative as well as the basal-like subtypes are characterized by an adverse course of disease and the need for adjuvant chemotherapy, even though the optimal regimens (platinum-based chemotherapy, PARP inhibitors) are the current focus of ongoing clinical trials [30].

The detection of disseminating tumor cells (DTCs) is an additional field of growing interest in breast cancer. The risk of distant recurrence is biologically based on minimal residual disease (MRD) which can be detected by the identification of DTCs in the bone marrow or circulating tumor cells (CTCs) in the blood. The relevance of DTCs as an independent prognostic parameter was demonstrated in several studies and in 1 metaanalysis [31]. However, so far, no routine detection method has been established since the therapeutic consequences are unclear. The detection of CTCs in peripheral blood is technically difficult, but a standardized FDA-approved assay is currently available. CTCs represent a validated prognostic marker in the metastasized situation and correlate with significantly shorter survival [32]. In the adjuvant situation, several studies were able to identify a prognostic value for CTCs [33]. However, since there is no proof of a clinical benefit resulting from therapeutic measures undertaken in response to the existence of CTCs, the detection of MRD cannot currently be recommended for routine use [3].

Multigene analyses offer the possibility of simultaneous investigation of multiple tumor-relevant pathways with the goal of identifying prognostic and predictive gene expression signatures [34]. Different test platforms are used to detect gene profiles. Quantitative reverse transcription polymerase chain reaction (qRT-PCR) and cDNA microarray are complex methods which also require complex mathematical algorithms to avoid false associations. The feasibility of these approaches was demonstrated in several retrospective studies, but the required prospective data are missing so far.

The Oncotype DX ${ }^{\mathrm{TM}}$ (Genomic Health Inc., Redwood City, CA, USA) assay is based on qRT-PCR to avoid the problem of fresh frozen tumor tissue, and uses readily available paraffin-embedded tumor blocks. A set of 250 genes was primarily analyzed in different study populations including the NSABP B-20 trial. The combination of gene expression could be linked to clinical outcome, and by applying a continuous variable algorithm, 3 risk categories could be defined low, intermediate, and high-risk - for developing distant metastases at 10 years. Finally, a 21-gene set (16 cancer-related, 5 reference genes) could be identified for the optimal discrimination of the 3 risk categories, and this set was validated in the NSABP B-14 trial in a population of ER-positive, node-negative patients who underwent endocrine therapy with tamoxifen [35]. The most dominant genes in this set can be grouped to proliferation (e.g. Ki-67), Her2/neu, and ERrelated genes. A recurrence score is calculated with low score $(<18)$, intermediate score $(>18$ and $<30)$, and high score ( $>30$ ). In the validation population of the NSABP B-14 trial, these score translated into a risk for distant recurrence of $7 \%$ (low), 14\% (intermediate), and 31\% (high), respectively [35, 36]. The molecular classification seems to better predict clinical outcome in comparison to conventional prognostic markers. A recently published retrospective study supported these findings and was able to show that up to $50 \%$ of patients who were classified with classical parameters to be at high risk could be downgraded to low risk by the utilization of Oncotype DX [37]. Besides the validation data for tamoxifen treat- 
ment, retrospective analyses (including NSABP B-20) also revealed that node-negative patients had no benefit from an additional chemotherapy in the case of a low recurrence score [36]. However, until now, the AGO guidelines have not recommended the usage of this assay since prospective data are missing [3]. Several large prospectively designed multicenter trials (TAILORx, Plan B) are ongoing to evaluate Oncotype DX for treatment decision, especially with regard to chemotherapy.

A different approach for multigene analyses is the utilization of fresh frozen tissue by applying cDNA arrays. The most advanced and analyzed assay is the MammaPrint ${ }^{\mathrm{TM}}$ (Trommsdorff GmbH \& Co. KG, Alsdorf, Germany) using a 70-gene signature. Starting from 25,000 genes, the Amsterdam group analyzed the clinical outcome (endpoint: distant-free survival) of 78 patients $<55$ years of age with node-negative tumors less than $5 \mathrm{~cm}$ which were ER-positive or -negative. The retrospectively chosen validation cohort proofed the 70-gene signature to be a potent discriminator for a good versus bad prognosis with a 10 -year survival of 85 vs. $51 \%$, respectively [15]. A further multicentre validation study of 300 untreated primary breast cancer patients exposed the potential prognostic significance of the assay by showing a hazard ratio of 4.6 vs. 2.1 for patients with a bad prognosis in comparison to a good prognosis signature [38]. Even if these data for multigene signatures are promising, the clinical value is so far not proven since no prospective data exist. The MammaPrint assay is currently the subject of a large prospective international trial (MINDACT of the BIG study group) to validate its prognostic power. Therefore, the current AGO guidelines do not recommend the clinical utilization of this test outside of clinical trials [3].

In the daily clinical setting, the established classical prognostic and predictive biomarkers still represent the backbone for treatment decisions with the highest clinical value. Some innovative markers, like uPA/PA-1, also represent solid and highly validated tools to guide treatment decisions, especially in certain subgroups of patients with early breast cancer, even if long-term data are mostly unavailable. It is of big importance to note that the innovative multigene approaches potentially will open a new chapter in breast cancer therapy but currently fail to reach the required validation level for routine clinical use. Besides all the discussed factors, additional risk modifiers such as lifestyle (obesity, alcohol consumption) have proven influence on disease outcome in breast cancer patients and should as a consequence be considered and verbalized in the communication with the patient.

\section{References}

1 Group EBCTC: Effects of chemotherapy and hormonal therapy for early breast cancer on recurrence and 15-year survival: an overview of the randomised trials. Lancet 2005;365:1687-717.

2 Harris L, Fritsche H, Mennel R, Norton L, Ravdin P, Taube S, Somerfield MR, Hayes DF, Bast RC Jr: American Society of Clinical Oncology 2007 update of recommendations for the use of tumor markers in breast cancer. J Clin Oncol 2007;25:5287-312.

3 AGO: Guidelines of the AGO Breast Committee: diagnosis and treatment of patients with primary and metastatic breast cancer. AGO, 2011; www.ago-online.org.

$\checkmark 4$ Aebi S, Gelber S, Castiglione-Gertsch M Gelber RD, Collins J, Thurlimann B, Rudenstam CM, Lindtner J, Crivellari D, Cortes-Funes H, Simoncini E, Werner ID, Coates AS, Goldhirsch A: Is chemotherapy alone adequate for young women with oestrogen-receptor-positive breast cancer? Lancet 2000;355:1869-74.

$\checkmark 5$ Arriagada R, Le MG, Dunant A, Tubiana M, Contesso G: Twenty-five years of follow-up in patients with operable breast carcinoma: correlation between clinicopathologic factors and the risk of death in each 5-year period. Cancer 2006;106:743-50.

6 Weiss RB, Woolf SH, Demakos E, Holland JF, Berry DA, Falkson G, Cirrincione CT, Robbins A, Bothun S, Henderson IC, Norton L: Natural history of more than 20 years of node-positive primary breast carcinoma treated with cyclophosphamide, methotrexate, and fluorouracil-based adjuvant chemotherapy: a study by the Cancer and Leukemia Group B. J Clin Oncol 2003;21:1825-35.
7 Reed W, Hannisdal E, Boehler PJ, Gundersen S, Host H, Marthin J: The prognostic value of p53 and c-erb B-2 immunostaining is overrated for patients with lymph node negative breast carcinoma: a multivariate analysis of prognostic factors in 613 patients with a follow-up of 14-30 years. Cancer 2000;88:804-13.

8 Elston CW, Ellis IO: Pathological prognostic factors in breast cancer. I. The value of histological grade in breast cancer: experience from a large study with long-term follow-up. Histopathology 1991;19:403-10.

9 Kroman N, Jensen MB, Wohlfahrt J, Mouridsen HT, Andersen PK, Melbye M: Factors influencing the effect of age on prognosis in breast cancer: population based study. BMJ 2000;320: 474-8.

10 Kollias J, Elston CW, Ellis IO, Robertson JF, Blamey RW: Early-onset breast cancer - histopathological and prognostic considerations. Br J Cancer 1997;75:1318-23.

11 Van de Vijver MJ, He YD, van't Veer LJ, Dai H, Hart AA, Voskuil DW, Schreiber GJ, Peterse JL, Roberts C, Marton MJ, Parrish M, Atsma D, Witteveen A, Glas A, Delahaye L, van der Velde T, Bartelink H, Rodenhuis S, Rutgers ET, Friend SH, Bernards R: A gene-expression signature as a predictor of survival in breast cancer. N Engl J Med 2002;347:1999-2009.

12 Goldhirsch A, Glick JH, Gelber RD, Coates AS, Thurlimann B, Senn HJ: Meeting highlights: international expert consensus on the primary therapy of early breast cancer 2005. Ann Oncol 2005;16:1569-83.
3 Schoppmann SF, Bayer G, Aumayr K, Taucher S, Geleff S, Rudas M, Kubista E, Hausmaninger H, Samonigg H, Gnant M, Jakesz R, Horvat R: Prognostic value of lymphangiogenesis and lymphovascular invasion in invasive breast cancer. Ann Surg 2004;240:306-12.

14 Vincent-Salomon A, Carton M, Zafrani B, Freneaux P, Nicolas A, Massemin B, Fourquet A, Clough K, Pouillart P, Sastre-Garau X: Long term outcome of small size invasive breast carcinomas independent from angiogenesis in a series of 685 cases. Cancer 2001;92:249-56.

15 Von Minckwitz G, Untch M, Nuesch E, Loibl S, Kaufmann M, Kummel S, Fasching PA, Eiermann W, Blohmer JU, Costa SD, Mehta K, Hilfrich J, Jackisch C, Gerber B, du Bois A, Huober J, Hanusch C, Konecny G, Fett W, Stickeler E, Harbeck N, Muller V, Juni P: Impact of treatment characteristics on response of different breast cancer phenotypes: pooled analysis of the German neo-adjuvant chemotherapy trials. Breast Cancer Res Treat 2011;125:145-56.

16 EBCTCG Esobo: Highlights from the early breast cancer trialist collaborative group (EBCTCG) 2005-2006 worldwide overview. Breast Cancer Res Treat 2009;100(suppl 1):abstr 40.

17 Remmele W, Stegner HE: (Recommendation for uniform definition of an immunoreactive score (IRS) for immunohistochemical estrogen receptor detection (ER-ICA) in breast cancer tissue). Pathologe 1987;8:138-40.

18 Goldhirsch A, Ingle JN, Gelber RD, Coates AS, Thurlimann B, Senn HJ: Thresholds for therapies: highlights of the St Gallen International Expert Consensus on the primary therapy of early breast cancer 2009. Ann Oncol 2009;20:1319-29. 
19 Pritchard KI, Shepherd LE, O'Malley FP, Andrulis IL, Tu D, Bramwell VH, Levine MN: HER2 and responsiveness of breast cancer to adjuvant chemotherapy. $\mathrm{N}$ Engl $\mathrm{J}$ Med 2006;354:2103-11.

20 Gonzalez-Angulo AM, Litton JK, Broglio KR, Meric-Bernstam F, Rakkhit R, Cardoso F, Peintinger F, Hanrahan EO, Sahin A, Guray M, Larsimont D, Feoli F, Stranzl H, Buchholz TA, Valero V, Theriault R, Piccart-Gebhart M, Ravdin PM, Berry DA, Hortobagyi GN: High risk of recurrence for patients with breast cancer who have human epidermal growth factor receptor 2-positive, node-negative tumors $1 \mathrm{~cm}$ or smaller. J Clin Oncol 2009;27:5700-6.

21 Piccart-Gebhart MJ, Procter M, Leyland-Jones B, Goldhirsch A, Untch M, Smith I, Gianni L, Baselga J, Bell R, Jackisch C, Cameron D, Dowsett M, Barrios CH, Steger G, Huang CS, Andersson M, Inbar M, Lichinitser M, Lang I, Nitz U, Iwata $H$, Thomssen $C$, Lohrisch $C$, Suter TM, Ruschoff J, Suto T, Greatorex V, Ward C, Straehle C, McFadden E, Dolci MS, Gelber RD: Trastuzumab after adjuvant chemotherapy in HER2-positive breast cancer. N Engl J Med 2005;353:1659-72.

22 Romond EH, Perez EA, Bryant J, Suman VJ, Geyer CE Jr, Davidson NE, Tan-Chiu E, Martino S, Paik S, Kaufman PA, Swain SM, Pisansky TM, Fehrenbacher L, Kutteh LA, Vogel VG, Visscher DW, Yothers G, Jenkins RB, Brown AM, Dakhil SR, Mamounas EP, Lingle WL, Klein PM, Ingle JN, Wolmark N: Trastuzumab plus adjuvant chemotherapy for operable HER2-positive breast cancer. N Engl J Med 2005;353:1673-84.

23 Look MP, van Putten WL, Duffy MJ, Harbeck N, Christensen IJ, Thomssen C, Kates R, Spyratos F, Ferno M, Eppenberger-Castori S, Sweep CG, Ulm K, Peyrat JP, Martin PM, Magdelenat H, Brunner N, Duggan C, Lisboa BW, Bendahl PO, Quillien V, Daver A, Ricolleau G, Meijervan Gelder ME, Manders P, Fiets WE, Blankenstein MA, Broet P, Romain S, Daxenbichler G, Windbichler G, Cufer T, Borstnar S, Kueng W, Beex LV, Klijn JG, O'Higgins N, Eppenberger U, Janicke F, Schmitt M, Foekens JA: Pooled analysis of prognostic impact of urokinase-type plasminogen activator and its inhibitor PAI-1 in 8377 breast cancer patients. J Natl Cancer Inst 2002;94:116-28.
24 Harbeck N, Schmitt M, Meisner C, Friedel C, Untch M, Schmidt M, Lisboa B, Sweep CG, Jänicke F, Thomssen C: Final 10-year analysis of prospective multicenter Chemo No trail for validation of ASCO recommended biomarkers uPA/PAI-1 for therapy decision making in node negative breast cancer. J Clin Oncol 2009; 27(suppl):abstr 511.

25 Viale G, Giobbie-Hurder A, Regan MM, Coates AS, Mastropasqua MG, Dell'Orto P, Maiorano E, MacGrogan G, Braye SG, Ohlschlegel C, Neven P, Orosz Z, Olszewski WP, Knox F, Thurlimann B, Price KN, Castiglione-Gertsch M, Gelber RD, Gusterson BA, Goldhirsch A: Prognostic and predictive value of centrally reviewed Ki-67 labeling index in postmenopausal women with endocrine-responsive breast cancer: results from Breast International Group Trial 1-98 comparing adjuvant tamoxifen with letrozole. J Clin Oncol 2008;26:5569-75.

26 Perou CM, Sorlie T, Eisen MB, van de Rijn M, Jeffrey SS, Rees CA, Pollack JR, Ross DT, Johnsen H, Akslen LA, Fluge O, Pergamenschikov A, Williams C, Zhu SX, Lonning PE, Borresen-Dale AL, Brown PO, Botstein D: Molecular portraits of human breast tumours. Nature 2000;406:747-52.

27 Sorlie T, Perou CM, Tibshirani R, Aas T, Geisler S, Johnsen H, Hastie T, Eisen MB, van de Rijn M, Jeffrey SS, Thorsen T, Quist H, Matese JC, Brown PO, Botstein D, Eystein Lonning P, Borresen-Dale AL: Gene expression patterns of breast carcinomas distinguish tumor subclasses with clinical implications. Proc Natl Acad Sci U S A 2001;98:10869-74.

28 Soerjomataram I, Louwman MW, Ribot JG, Roukema JA, Coebergh JW: An overview of prognostic factors for long-term survivors of breast cancer. Breast Cancer Res Treat 2008;107:309-30.

29 Cheang MC, Chia SK, Voduc D, Gao D, Leung S, Snider J, Watson M, Davies S, Bernard PS, Parker JS, Perou CM, Ellis MJ, Nielsen TO: Ki67 index, HER2 status, and prognosis of patients with luminal B breast cancer. J Natl Cancer Inst 2009;101:736-50.

30 Foulkes WD, Smith IE, Reis-Filho JS: Triple-negative breast cancer. N Engl J Med 2010;363:1938-48.
Braun S, Vogl FD, Naume B, Janni W, Osborne MP, Coombes RC, Schlimok G, Diel IJ, Gerber B, Gebauer G, Pierga JY, Marth C, Oruzio D, Wiedswang G, Solomayer EF, Kundt G, Strobl B, Fehm T, Wong GY, Bliss J, Vincent-Salomon A, Pantel K: A pooled analysis of bone marrow micrometastasis in breast cancer. N Engl J Med 2005;353:793-802.

32 Cristofanilli M, Budd GT, Ellis MJ, Stopeck A, Matera J, Miller MC, Reuben JM, Doyle GV Allard WJ, Terstappen LW, Hayes DF: Circulating tumor cells, disease progression, and survival in metastatic breast cancer. $\mathrm{N}$ Engl $\mathrm{J}$ Med 2004;351:781-91.

33 Pachmann K, Camara O, Kavallaris A, Krauspe S, Malarski N, Gajda M, Kroll T, Jorke C, Hammer U, Altendorf-Hofmann A, Rabenstein C, Pachmann U, Runnebaum I, Hoffken K: Monitoring the response of circulating epithelial tumor cells to adjuvant chemotherapy in breast cancer allows detection of patients at risk of early relapse. J Clin Oncol 2008;26:1208-15.

34 Sparano JA, Fazzari M, Kenny PA: Clinical application of gene expression profiling in breast cancer. Surg Oncol Clin N Am;19:581-606.

35 Paik S, Shak S, Tang G, Kim C, Baker J, Cronin M, Baehner FL, Walker MG, Watson D, Park T, Hiller W, Fisher ER, Wickerham DL, Bryant J, Wolmark N: A multigene assay to predict recurrence of tamoxifen-treated, node-negative breast cancer. N Engl J Med 2004;351:2817-26.

36 Paik S, Tang G, Shak S, Kim C, Baker J, Kim W, Cronin M, Baehner FL, Watson D, Bryant J, Costantino JP, Geyer CE Jr, Wickerham DL, Wolmark N: Gene expression and benefit of chemotherapy in women with node-negative, estrogen receptor-positive breast cancer. J Clin Oncol 2006;24:3726-34.

37 Marchionni L, Wilson RF, Wolff AC, Marinopoulos S, Parmigiani G, Bass EB, Goodman SN: Systematic review: gene expression profiling assays in early-stage breast cancer. Ann Intern Med 2008;148:358-69.

38 Buyse M, Loi S, van’t Veer L, Viale G, Delorenzi M, Glas AM, d'Assignies MS, Bergh J, Lidereau R, Ellis P, Harris A, Bogaerts J, Therasse P, Floore A, Amakrane M, Piette F, Rutgers E, Sotiriou C, Cardoso F, Piccart MJ: Validation and clinical utility of a 70-gene prognostic signature for women with node-negative breast cancer. J Natl Cancer Inst 2006;98:1183-92. 